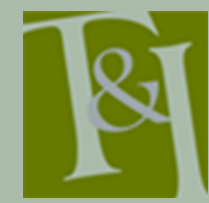

The International Journal for Translation \& Interpreting Research trans-int.org

\title{
The impact of emotional and psychological factors on public service interpreters: Preliminary studies
}

\author{
Carmen Valero Garcés \\ Universidad de Alcalá de Henares, Madrid \\ carmen.valero@uah.es
}

DOI: 10.12807/ti.107203.2015.a07

\begin{abstract}
The impact of psychological and emotional factors on public service interpreters is widely accepted by those working in the field, yet studies on the matter remain sparse. Drawing on research conducted in the early $21^{\text {st }}$ century, this paper presents various preliminary studies (Master theses) by students of the European Masters in Intercultural Communication, Public Service Interpreting and Translation at the Universidad de Alcalá de Henares (Madrid, Spain). The main objective of the current review is to determine whether conclusions from previous research are reproducible in new contexts (in particular, the context explored is Spain in the second decade of the $21^{\text {st }}$ century). The subject matter of the studies includes challenges facing non-professional interpreters in different settings; the influence of emotional and psychological factors on conference interpreters, public service interpreters and public service interpreting (PSI) students; interpreting in mental health; and burnout syndrome in PSI. Data for the research has been drawn from interviews and questionnaires. A review of past research on PSI illustrates that interpreters in public services perform their task in challenging settings that are fraught with delicate content, that they are exposed to significant psychological and emotional stress, are expected to perform numerous occupational tasks, and finally, that they are subjected to ever-changing physical, psychological and environmental conditions. The subsequent review of more recent research lends further credibility to past findings and furthermore highlights the need for training in coping with the situations and tensions that have been demonstrated to affect the PSI interpreter's work.
\end{abstract}

Key words: public service interpreting, community interpreting, emotional impact, psychological impact, stress.

\section{Introduction: A short review of past research on the influence of emotional and psychological factors in PSI}

Studies conducted at the close of the $20^{\text {th }}$ and early $21^{\text {st }}$ century have found that interpreters who work in public service interpreting (PSI) - also known as community interpreting (CI) - frequently face circumstances that may be detrimental to their emotional and psychological well-being. Such circumstances may even give rise to grave consequences in some cases. Studies by L. Loutan et al. (1999), Baistow (2000), and the author (2006) offer examples.

Research by L. Loutan, T. Farinelli and S. Pampallona at the University Hospital in Geneva in 1999 was sparked by an interest in exploring the effects of exposure to traumatic experiences and the emotional impact that these experiences have on interpreters. The findings are based on survey responses by 18 of the 22 members of the Red Cross interpreter service. (Although 19 participants responded [86\% response rate], one incomplete survey was not included in the analysis). The results indicate that a very high percentage 
(almost 100\%) of the interpreters surveyed had in fact endured difficult life circumstances themselves. Another $28 \%$ had been exposed to major traumatic events: war, torture, detention, and injury inflicted by others. Regarding the content of the consultations they interpreted, seven of the 18 respondents (39\%) reported that more than half of their commissions dealt with violence.

In order to evaluate the effects of interpreting for such encounters, participants responded to questions about feelings and symptoms related to their work. Results indicated that $28 \%$ of participants often dealt with difficult emotions during the sessions, $66 \%$ experienced frequent painful memories of the sessions, and $83 \%$ encountered patients for whom they had interpreted outside the consultation on another occasion.

The most frequent symptoms reported by participants were nightmares, depression, and insomnia. The interpreters expressed an interest in debriefing with the service provider post-session in order to discuss their reactions. The authors recommend that doctors be aware of the pressures and challenges that face interpreters in this context and propose that they allow interpreters time to share their emotions in order to cope better. They also suggest regular informative pre- and post-sessions (debriefings) for interpreters with group supervision as seen fit.

The second study, by Baistow (2000), surveyed nearly 300 PSI interpreters in six European countries and found that more than half of the respondents (55\%) reported "significant emotional stress" arising from their work or the circumstances of their clients. Baistow determined that the emotions felt most frequently in connection with interpreting - stress, frustration and grief - were also the emotions experienced most strongly. Approximately $39 \%$ of the participants reported sometimes experiencing strong feelings of anxiety, irritability, fear, mood swings, confusion or feeling disturbed during an assignment, whereas $38 \%$ reported experiencing these emotions rarely, $15 \%$ never, and $8 \%$ reported experiencing them often.

Following Baistow's study, the author (2006) conducted research at the Escuela de Mediadores Sociales para la Inmigración (EMSI, the School of Social Mediators for Immigration) in 2003 in Madrid, Spain. EMSI was by that time an official institution that trained social mediators for immigration. Although research was carried out during a period of relatively high immigration rates in Spain, professional translation and interpreting services remained non-existent. Rather, interpreters were usually ad hoc volunteers who regularly served with non-profit organizations (NGOs) or other institutions.

A total of 40 sets of data was collected from EMSI students, who had been working as interpreters. Three-quarters $(75 \%)$ of these student-interpreters were immigrants. Most respondents reported working or having worked for more than one particular institution or service: $58.3 \%$ worked in NGOs, $20.8 \%$ in courts, $20.8 \%$ in state offices and $41.7 \%$ in other institutions. The greatest challenges that the interpreters faced were maintaining neutrality $(66.7 \%)$, discomfort with the topic at hand $(62.5 \%)$, being affected by the distress and anxiety of the service users (54.2\%), and feeling powerless to be able to help clients directly $(50 \%)$.

When asked about the availability of a support system or other services for interpreters in the agencies or service centres where they normally worked, $75 \%$ reported that such a service did not exist, $4.2 \%$ reported that although such a service existed, they had not used it, $8.3 \%$ reported that such a service existed and that they had used it, and $12.5 \%$ gave no answer. (Respondents were permitted to select more than one answer.) The coping strategies that they reported using include speaking with co-workers (not necessarily interpreters) $(41.7 \%)$, friends $(37.5 \%)$, other interpreters $(33 \%)$, and family members or other relatives (33\%). Only 8.3\% discussed their emotional burden with health care professionals or support staff at their place of employment (such as human resources divisions). 
Other studies that document the emotional impact of interpreting include those conducted by Cole (2010), who reported post-traumatic stress in interpreters associated with the hearings of the South African Truth and Reconciliation Commission; Westermeyer (1990), who found a potential increase in vulnerability to psychiatric disorders in interpreters who have the same origin as the refugees for whom they interpret; and Rokenes (1999) in Norway, who determined that $66 \%$ of the interpreters surveyed experienced emotional reactions "now and again" that made their work difficult. More recently, Bontempo and Napier (2011, p. 87) proposed that in addition to general cognitive ability (linguistic proficiency, intelligence, working memory, processing speed and so on), an interpreter's performance might also be influenced by affective factors inherent to the interpreter (e.g., self-efficacy, goal orientation and negative affectivity). Although the researchers conclude that data were insufficient to determine whether emotional stability is a salient predictor of interpreter performance, they point out prior research that suggests that the capacity to control stress is a prerequisite for interpreting (Brisau et al., 1994; Kurz, 2003; Moser-Mercer, 1985), in addition to Gile's (1995) assertion that interpreters must possess the sort of personality that allows them to perform under high stress in the presence of the communicating parties, where stakes may be very high and the risk of failure is ever present.

The aforementioned studies lend credibility to the influence of emotional and psychological factors in predicting work performance in public service interpreting. It is also worth mentioning that all these studies provide recommendations for the improvement of interpreter well-being, including the need to incorporate training on coping into interpreting programmes. Such training might include information on emotionally demanding subjects, how to recognize factors for stress risk, symptom identification, and strategy development for dealing with psychological trauma. Despite documentation of the need for training in managing interpreter stress, this issue has received little attention from the organizations where interpreters provide their services.

\section{Emotional and psychological impact in PSI interpreting: case studies by M.A. students in Spain}

More than a decade after the publication of the studies reviewed above, a number of preliminary studies were conducted in Spain by postgraduate students of the European Masters in Intercultural Communication, Public Service Interpreting and Translation (MICIT), ${ }^{1}$ with the intention of determining whether any changes have taken place in the impact of emotional and psychological factors on PSI interpreters. The following is a review of some of these Masters theses, organized in three sections.

The first set of studies includes research by Wasko (2009), Pérez Rodriguez (2011), and Svakova (2011), based on the perspective of interpreters themselves on the influence that emotional and psychological factors have on them, as well as the availability of resources and coping strategies. The second section comprises two studies that compare the influence of emotional and psychological factors, based on interpreter type: one compares professional interpreters and interpreting students (Bošković, 2010), while the other compares conference and PSI interpreters (Olalla, 2011). The third grouping focuses on issues specific to mental health interpreting (Musacchio, 2013) and

${ }^{1}$ The European Masters in Intercultural Communication, Public Service Interpreting and Translation (MICIT), inaugurated in 2005, is offered in ten language combinations (Spanish paired with Arabic, Bulgarian, Chinese, English, French, German, Polish, Portuguese, Romanian and Russian) (http://www3.uah.es/master-tisp-uah) and is a member of the European Master's in Translation Network (EU-DGT EMT: http://ec.europa.eu/dgs/translation/programmes/emt/index_e.htm).

Translation \& Interpreting Vol 7 No 3 (2015) 
the influence of burnout syndrome in PSI (Cordero Cid, 2013). This preliminary research helps to shed light on the possible impact that emotional strain might have on interpreter performance and may imply the need for further research.

\subsection{Challenges facing non-professional interpreters in PSI: Case studies}

The stressful nature of PSI interpreting is more widely accepted a decade after research began on the profession's emotional impact. Nevertheless, progress seems to be almost imperceptible in Spain and probably in other communities as well. With the exception of the studies introduced below, literature on the topic remains scarce, if not non-existent.

The research reviewed in this first series of studies includes information and data regarding the challenges of interpreting in the health care sector in Spain (Wasko, 2009); the consequences of interpreting in different settings and resources available for coping (Pérez Rodríguez, 2011); and the psychological impact of interpreting in the public service sector at three different points in the assignment: before, during and after the interpreted session (Svakova, 2011). A summary of these studies and their conclusions follow.

Wasko (2009) sought to determine whether health care interpreters are to be counted among those professionals at risk of suffering psychological and emotional trauma stemming from the nature of the tasks they perform. Data come from 12 interviews conducted in person with interpreters, each lasting approximately 20-40 minutes. The interview included open questions related to the psychological and emotional impacts affecting interpreters in the health care sector, the difficulties they encounter when carrying out these tasks, the possible need for intercultural mediation as well as the attitude of medical staff and patients towards the interpreter's presence and the interpreter's role. Given that interpreting remained unrecognized as a profession in Spain at the time that the research was being conducted, interviewees were all ad hoc interpreters, that is to say they were volunteer interpreters with experience but no training. In addition to the interviews with interpreters, Wasko also proposed interviews with doctors. The majority of the doctors asked (5 out of 8 ) declined participation in the survey, citing that they had never worked with interpreters. Ultimately, 3 doctors were interviewed.

Responses from all the interpreters surveyed (100\%) supported the author's postulation that the tasks associated with health care interpreting influence one's psychological well-being. Participants cited the suffering experienced by those they interpret for as the most common source of stress. Indeed interpreting services are most often required by immigrants, many of whom lack a support system in the host country and lack knowledge of how to manage the many obstacles they must face in order to remain in the new country. When describing the challenges they encountered in interpreting, 90\% of respondents reported difficulty in separating oneself from the grief of those they interpret for. The following testimony from one of the participants illustrates this point: "The hardest thing is not being able to help them in their lives. People are hungry and I have a computer, an apartment...."

The interviews also asked participants to describe the ways in which they care for their own wellbeing: $70 \%$ mentioned physical relaxation, exercise, rest, and talking to friends and family. In discussing stress, not all of those interviewed agreed (40\%) with the statement that the health care interpreter's job is more stressful than that of interpreters in other settings. However, it is worth noting that those interviewed interpreted only occasionally.

In response to a question on the attitude that medical staff and patients have towards the interpreter, all the interviewees confirmed that the reaction is usually positive. As for the perspective of medical staff, those interviewed (3) admitted that although they had not seen many cases where an interpreter was required, patients seemed very grateful to be able to express themselves in their native language without either having to rely on the presence of an acquaintance 
or family member or attempting to communicate in an unfamiliar language on their own. When asked about the role of the health care interpreter, doctors confirmed the need for assistance during encounters with foreign patients, especially in providing explanations of sociocultural differences or other tasks outside the professional profile, such as filling out forms, making phone calls, or sorting out administrative matters. Wasko concludes by emphasizing that issues related to workers' emotional well-being continue to be disregarded even in the $21^{\text {st }}$ century and urges for action.

In the second preliminary study Pérez Rodríguez (2011) investigates the consequences of interpreting in different settings (health care, law and education) and looks at various coping strategies. The data come from the study of real-life cases and survey responses by interpreters (30) on their perception of the challenges in PSI. The results revealed the following: In response to a question on when they were most likely to experience discomfort in an interpreted session, answers included (from the most to least frequent) disputes, client anxiety, negotiations, social vulnerability, child abuse, domestic abuse, the presence of corpses, and discrimination. The most common symptoms that they described were feeling pressure (49\%) and stress (20\%), but some also reported anguish (10\%), difficulty in remaining impartial (7\%), anxiety (7\%) and increased heart rate $(7 \%)$.

Pérez Rodriguez's study also offers information on a small number of organizations and institutions that recognise risks for interpreters and offer psychological support to interpreters (day or half-day seminars and two-hour sessions). However, the author found that interpreters were often unaware of these resources.

Pérez Rodriguez's most salient finding was that interpreters who work in public services are constantly exposed to traumatic situations that can directly or indirectly impact on both their physical and psychological health. Various symptoms and mental conditions may arise as a result, which in many cases become aggravated if the interpreters remains unaware of them and do not seek psychological or medical treatment. The study also suggests that the onset of these symptoms often occurs in relation to negative experiences or trauma in the interpreter's own past, given that many interpreters are immigrants themselves and have endured similar incidents. Furthermore, the interpreters often lack specific training. The author also notes the importance of the interpreter's personality (whether they suffer from insecurity, nervousness or low self-esteem) in the effect their work may have on them.

In the third study, Svakova's (2011) aim was to analyse the psychological and emotional impact on interpreters working in public services at three specific points in the interpreting task: before, during, and after. Data come from questionnaires completed by 20 experienced interpreters (where experience is defined as having interpreted for more than 50 hours without any formal training). The interpreters interpreted in hospitals, courts, and non-profit organizations (some in all three settings).

Responses to questions on the period of time and preparation before an interpreting assignment revealed that the majority of those surveyed (55\%) prepared ahead of time by doing research based on the assignment setting as a way to avoid stress and other adverse outcomes. As for factors related to the interpreted session itself, the type of setting was cited as one contributor to stress. Palliative care $(60 \%)$, prison $(55 \%)$ and refugee centres $(50 \%)$ were the settings that were considered the most challenging. All participants were also prompted to comment on the difficulties that arise in interpreted sessions and whether they themselves observe a code of conduct. The difficulty most often cited $(60 \%)$ was - in one interpreter's words - that "it was difficult to put theory into practice and follow the principle of impartiality and professional distance." This tendency was attributed to both the interpreters' own experiences and their desire to help others. Another motive for breaking impartiality was 
encountering a situation that contradicted the interpreter's values, making it difficult to maintain detachment. The following account illustrates this point:

Two times I was on the verge of rejecting the interpreting assignment. One time because it had to do with abortion and I am against abortion due to moral and religious norms. The second time it was about a marriage of convenience. During both interpretations I felt very uncomfortable and I don't plan on accepting these kinds of interpreting assignments in the future (Svakova, 54)

Finally, with regard to the post-interpreting stage, participants were asked whether the organization or institution where they interpreted offered any sort of psychological support. All participants (100\%) answered no. Some reported that they simply do not seek out support (30\%), while others looked to friends $(30 \%)$, co-workers $(20 \%)$ or a family member $(15 \%)$, and only a very small percentage sought specialized care (5\%).

All respondents agreed that interpreting in complicated situations or for highly emotional content can produce negative psychosocial consequences. Stress, nervousness and direct trauma were among their concerns, and some even described experiencing difficulties in work relationships as a result. The author of the study concludes that organizations and institutions that employ interpreters should be urged to create favourable conditions for interpreters to help them cope with the inherent challenges.

\subsection{Comparing the influence of emotional and psychological factors on conference interpreters, PSI interpreters and interpreting students: case studies}

This section will explore two preliminary studies that compare the impact that psychological factors have on interpreters, depending on their training and experience and the setting. The first study compares the stress experienced by interpreting students with that of professional interpreters in PSI (Bošković, 2010), while the second examines the influence of psychological factors on PSI interpreters compared to conference interpreters (Navarro Moreno, 2010).

Bošković's (2010) research examines the role of stress on interpreting students using role-plays in class compared to the factors that influence stress in professional interpreters. Data come from a survey conducted in two groups: 1) interpreting students from the European Masters in Intercultural Communication, Public Service Interpreting and Translation at the Universidad de Alcalá de Henares (20), and 2) professional PSI interpreters in Spain (13). The main conclusion was that the two groups, both novice and professional interpreters, felt stress to be a significant concern, although its source varied depending on the group.

Students participating in the study had received 100 hours of on-site training in interpreting, including terminology, role plays, and simulated situations with real health care staff (nurses, doctors, etc.). The students' fears, when compared to those of practising interpreters (Table 1), seemed to reflect the students' anxiety about following instructions given in class and obtaining the best possible grade rather than a preoccupation with the gravity of the public service interpreter's task. This was made evident by the situations that students found most threatening out of the ten provided (below): a lack of knowledge of the language or terms used (23\%), not understanding the dialect or the speaker's accent $(12 \%)$, and losing track of what was being said in the conversation (12\%). In contrast, practising interpreters showed greater distress about aspects of interpreting that related to external factors rather than the act of interpreting itself. Their biggest concerns were feeling pressure due to the importance of the assignment (16\%), difficult behaviour on the part of the speakers $(14 \%)$, and lack of time to prepare for the assignment (13\%). 
Table 1. The most common causes of stress among students and interpreters surveyed

\begin{tabular}{|l|l|l|}
\hline \multicolumn{3}{|l|}{ Most common causes of stress among students and interpreters surveyed } \\
\hline Lack of knowledge of the language or terms used & PSI students & PSI interpreters \\
\hline $\begin{array}{l}\text { Lack of understanding of the speaker's accent or } \\
\text { dialect }\end{array}$ & $12 \%$ & $12 \%$ \\
\hline $\begin{array}{l}\text { Losing track of what is being said in the } \\
\text { conversation }\end{array}$ & $12 \%$ & $9 \%$ \\
\hline $\begin{array}{l}\text { Feeling pressure due to the importance of the work } \\
\text { being performed }\end{array}$ & $11 \%$ & $9 \%$ \\
\hline $\begin{array}{l}\text { Inadequate physical conditions (noise, poor } \\
\text { ventilation and acoustics, etc.) }\end{array}$ & $10 \%$ & $16 \%$ \\
\hline $\begin{array}{l}\text { Content of what is being interpreted (war, rape, } \\
\text { suffering, etc.) }\end{array}$ & $10 \%$ & $12 \%$ \\
\hline Lack of concentration or good memory & $8 \%$ & $4 \%$ \\
\hline Speakers' misbehaviour & $5 \%$ & $14 \%$ \\
\hline Lack of time to prepare for assignment & $5 \%$ & $13 \%$ \\
\hline Fear of speaking in public (e.g. Ina trial) & $4 \%$ & $2 \%$ \\
\hline
\end{tabular}

The disparity between interpreting students and practising interpreters as illustrated in the data may be explained in part by the differing characteristics inherent to role-plays versus genuine interpreting assignments. In other words, regardless of the quality of training that students receive, there is a limit to how closely a simulated situation can approximate a real assignment. This leads us to believe that experience is a critical factor to be taken into account in assessing stress in interpreters.

Márquez Olalla's study (2013) deals with stress experienced by interpreters, depending on the setting. The author focused specifically on the anxiety experienced by conference interpreters compared to public service interpreters and whether there was variation in the triggers and consequences of the anxiety. Data come from interviews (2 with PSI interpreters and 4 with conference interpreters) and questionnaires (15 from PSI interpreters and 11 from conference interpreters). The main conclusion derived from the study was that although both types of interpreters suffered from stress, the sources of their anxiety varied.

Overall, the conference interpreters indicated that the stress they suffer stems mostly from difficulty in translating unknown terms on the spot and in finding solutions when they are unfamiliar with the topic or have not been given time to prepare for it. The conference interpreters also mentioned being affected by the pronunciation and intonation of their speakers and, to a lesser extent, the physical conditions in the auditorium or the booth.

The PSI interpreters, in contrast, indicated that their stress arises from the very context in which they interpret, or more precisely, from an element of it. They felt that a bond was created between themselves and the speakers particularly foreign speakers, whose experiences were in many cases similar to those of the interpreters themselves. The interviewees cited two explanations in particular for this bond: shared language and culture (especially in minority languages) and the interpreter's sense of compassion and desire to help the speaker. These situations, which have an emotional effect on the interpreter, make it difficult for them to maintain their role as someone who merely transmits information. The findings also indicated that PSI interpreters, like conference interpreters, are affected by terminology errors, especially because of the difficulties in determining the nature of the interpretation beforehand, impeding adequate preparation for the assignment.

Márquez Olalla concludes that the conference interpreter's performance is mostly affected by linguistic issues, whereas the PSI interpreter is more likely to suffer from extra-linguistic factors. Márquez Olalla's findings coincide with those of Bošković (2010), which show that emotions and other psychological 
components were given importance but that extra-linguistic factors also affected PSI interpreters. Importantly, these elements are precisely those that are often not included in training for PSI interpreters.

\subsection{Interpreting in mental health settings and burnout syndrome in PSI: two preliminary studies}

This section will discuss two preliminary studies on two more narrow topics that are nevertheless related: interpreting in mental health (Musacchio, 2013) and the influence of burnout syndrome in PSI (Cordero Cid, 2013).

The first study, by Musacchio (2013), concentrates on analysing the influence of stress on interpreters, patients and health care staff in the mental health setting. The central hypothesis was that listening to patients' histories of mental disorders could produce anxiety and stress for the interpreter and trigger uncomfortable memories and thoughts. The researcher also sought to determine whether immigrant patients attending mental health consultations tended to suffer from Immigrant Syndrome with Chronic and Multiple Stress (also known as Ulysses Syndrome) ${ }^{2}$ and whether this condition could also have a vicarious effect on the interpreter. Musacchio developed three different semi-structured surveys: one for immigrant patients (30 responses), one for doctors (10 responses) and one for interpreters ( 24 responses).

The patients' responses often revealed tragic circumstances. They also showed appreciation for the presence of an interpreter during the consultation, and reported that their presence did not alter the balance of the communication between patient and doctor - a finding that contradicts the opinion of some psychiatrists that the presence of a third and unknown element (the interpreter) could interfere with their work (Tribe \& Raval, 2002, p. 4).

The interviews conducted with mental health care staff (psychiatrists and psychologists) working with immigrant patients showed that these professionals felt an overall significant need to help patients, not just from a communicative standpoint (short sentences, ungrammatical structures, very simple vocabulary), but also from a cultural and psychological one. In fact, some doctors tended to exhibit signs of stress, nervousness and irritability due to incomprehension and misunderstandings - problems that can be resolved with the use of an interpreter.

However, the study also highlighted conflicting points of view among staff concerning the value of interpreters. This may indicate a lack of awareness of the interpreter's role on the part of the service provider, and the need for training of both medical staff and interpreters (particularly given that some interpreters who work as freelancers may have limited experience in the mental health setting). As Raval (2003, p. 13) points out, "In the context of therapy language and meaning are central to the therapeutic work. Mental health work goes beyond the 'simple translation' needed to answer specific social welfare or legal questions. Perhaps it then becomes more important that mental health work is carried out with professionally trained interpreters."

As for the perspective of the interpreters themselves, the results from the survey and interviews indicate that the more specialized the interpreter and the greater their knowledge of Ulysses Syndrome, the less they were affected by the patients' conditions and trauma. Some interpreters working in these

\footnotetext{
2 The Immigrant Syndrome with Chronic and Multiple Stress, also known as Ulysses Syndrome - a name coined by the psychiatrist Achotegui in 2002 - refers to a set of symptoms experienced by people who leave their countries of origin to settle in an unknown place. The syndrome is characterized by loneliness and a sense of despair and failure - symptoms that have been associated with a struggle to survive and the risks endured in the process of migrating and settling down (Achotegui, 2003). The symptoms most frequently detected by doctors are those of depression and anxiety, as well as somatic and dissociative symptoms, which can occur in members of the immigrant community as a consequence of complex or complicated migratory grief.
} 
consultations, however, did exhibit a deep emotional involvement. Based on the responses from the three groups, Musacchio concludes that working with sensitive issues such as mental disorders can cause stress for interpreters. However, patients suffering from these disorders exhibit more trust and feel more at ease in the interpreter's presence, thus benefitting from their contribution.

The second preliminary study that will be discussed in this section is that of Cordero Cid (2013), which concentrates on the assessment of a specific stress-related condition: burnout syndrome. Burnout, a term first coined in the field of psychology, ${ }^{3}$ refers to long-term exhaustion and diminished interest in work (Maslach, 1982, p. 4).

The main objective of this study was to observe the development of this syndrome among interpreters and to determine whether they had received any training on the matter or were aware of any other support resources available to them. Incidentally, Cordero Cid proposes a guide designed specifically for interpreters on the prevention of work-related stress based on her findings, in addition to a training proposal (discussed below).

Cordero Cid's findings are based on a survey adapted from the Maslach Burnout Inventory (MBI), the standard tool for measuring burnout in research (Maslach \& Jackobson, 1981; Maslach \& Leiter, 1997). There were 24 valid responses, of which $22(91.6 \%)$ showed a medium level of burnout (between 45 and 88 points), and $1(4.1 \%)$ a high level. With respect to the general training of those surveyed, over half of the respondents $(66.6 \%)$ stated that they had not received any training, while only $12.5 \%$ reported that they had received training through their company and $20.3 \%$ had attended courses of their own accord. Respondents worked in more than one setting (health care, law, social services).

Based on Cordero Cid's findings, it appears that the onset of burnout syndrome in interpreters is negatively correlated with experience, which suggests that more seasoned interpreters in PSI may have additional means at their disposal for dealing with the difficult situations that they encounter. Cordero Cid's study also indicates that interpreters do not receive information about burnout syndrome in their training, nor are there resources intended specifically for interpreters regarding the condition.

In addition to the above findings, Cordero Cid also evaluated which of the three defining components of burnout syndrome (emotional exhaustion, depersonalization and reduced personal accomplishment) had the most significant effect on interpreters. She concludes that reduced personal accomplishment was the most notable. This aspect may itself trigger a series of negative responses, including some directly related to work (irritability, low productivity, inability to deal with tension, loss of motivation, etc.). In terms of the symptoms stemming from contact with emotional content, the surveys indicate that interpreters experience symptoms such as depression (low mood, apathy, hopelessness, feelings of uselessness), anxiety (frustration due to not being able to offer more help, despair, and nervousness), and questioning one's use and that of the service they provide.

The final element in Cordero Cid's study involves interviews with professionals in the field of psychology (5) and aid workers (health care staff,

\footnotetext{
${ }^{3}$ Herbert Freudenberger coined the term burnout in his 1974 book Staff Burnout. There are many theories on burnout, most of which include negative outcomes in relation to the condition, including measures of job function (performance, output, etc.), health related outcomes (increases in stress hormones, coronary heart disease, circulatory issues, headaches, insomnia, etc.) and mental health problems such as depression and anxiety. One of the most recognized theories is that of Maslach and Jackson (1996), who first identified the construct of burnout in the 1970s and developed a measure that weighs the effects of emotional exhaustion and reduced sense of personal accomplishment (the Maslach Burnout Inventory). This indicator has become the standard tool for measuring burnout in research (Maslach \& Leiter, 1997).
}

Translation \& Interpreting Vol 7 No 3 (2015) 
social workers and trainers) (7). All the psychologists (100\%) believed that having direct contact with traumatic situations and those suffering from them could affect the work of interpreters. They also pointed to the need for preliminary training to prepare professionals for these situations. Below is a quote from one of the psychologists regarding training for interpreters:

...From my perspective, preparation would not be directed so much at developing aspects such as indifference or passivity (so that one can carry out his work by "keeping his composure"), but rather at developing more positive attitudes that would allow the interpreter to experience a social and emotional life based on empathy, comprehension and respect, without this leading to one becoming emotionally overwhelmed. Let's not forget that work is one of the main resources that a person has through which to develop and grow as a human being and that, in turn, those human qualities have direct implications for the workplace; this profound personal change could be the best way to guarantee that interpreting situations are coped with in an appropriate manner (Cordero Cid, p. 34).

Another psychologist suggests, “....at the very least, psychological support would help them not to "bring the work home with them." (Cordero Cid, p. 35)

In terms of the interviews with aid workers (health care workers, social workers, immigrant services workers, etc.), only around $30 \%$ indicated having received some training in coping with stress, but the majority of those surveyed felt that training was essential. Cordero Cid emphasizes the importance of training to cope with trauma, emotion and burnout in translation and interpreting programmes as well, especially those related to public services. Based on her findings, she offers a training proposal for interpreters and presents a one-page practical guide (Guide on Preventing Burnout for Public Service Interpreters). The training proposal, which is designed as a module to be integrated into future interpreting curricula, includes information and practical exercises on professional ethics, a description of work settings based on real-life cases, and material on emotional intelligence with the intention of helping prevent psychological and emotional trauma. The proposal also recommends internships in the field as a way for students to acquire experience and establish contacts in the professional world. The one-page guide, which was kept brief in order to facilitate ease of use, includes relaxation exercises and advice for before, during and after interpreted sessions.

\section{Conclusion}

The influence of psychological and emotional factors on interpreters in public service interpreting remains an issue that, despite its wide acceptance in the field, lacks sufficient support in the literature. The current paper intends to present numerous preliminary studies based on the limited but essential prior research. The review of prior research on public service interpreting provides evidence that interpreters perform their task in challenging settings that are fraught with delicate content, that they work under substantial psychological and emotional stress, are expected to perform numerous occupational tasks, and finally, that they are subjected to ever-changing physical, psychological and environmental factors.

The more recent preliminary research carried out as Master theses by students in the European Masters in Intercultural Communication, Public Service Interpreting and Translation (reviewed in the second section of the current article), gives further credence to past findings on the significance of the psychological impact in PSI interpreting, and moreover emphasizes the need for training to cope with the situations and tensions particular to the PSI interpreter's work. The main conclusions from the current review are the 
following: Public service interpreters are exposed to challenging settings and sensitive topics that can give rise to powerful psychological and emotional stress. This stress may be exacerbated by the very nature of the interpreter's task, which requires painstaking attention to the discourse of individuals who in many cases exhibit violent or nervous behaviour and have suffered trauma. Interpreters, many of whom are immigrants themselves with similar histories, must then render these messages in their own voice. In addition to stress provoked by the nature of the interpreted sessions, other common factors for stress may arise (physical, psychological or environmental). Clearly, numerous occupational demands such as mastering linguistic skills and acquiring the political, cultural, social and religious knowledge of the public service interpreting client, can affect the overall interpreting task and may contribute to interpreter stress and burnout. The high daily demands of the job can consume the interpreter's energy. Both current and future public service interpreters are subject to pressures that may affect their work and can impact physically and psychologically on their personal and professional lives.

The studies referenced in this article demonstrate the growing interest in studying stress in public service interpreting. The current literature includes numerous proposals for supporting interpreters in overcoming the documented burdens - training being the most frequent suggestion.

To conclude this article I would like to underscore my belief in the value of the type of research carried out by the MA students I have grouped here. Similar undertakings by other students have produced numerous studies of great relevance that help us to envision problems and their potential solutions, and moreover, to ask questions whose answers are often unknown not only to interpreter trainers and researchers, but also to experts in the field, institutional representatives and the general public. Indeed, research initiated by graduate students has had a substantial influence on current and upcoming advancements in public service interpreting and translation, both in design and implementation, and deserves to be encouraged and publicized. Finally, it is my hope that the studies reviewed herein may serve as a point of departure for more in-depth research. Further investigation and action are recommended.

\section{References}

Achotegui, J. (2002). La depresión en los inmigrantes: una perspectiva transcultural. Barcelona: Editorial Mayo.

Achotegui, J. (2003). Dossier of the International Meeting "The Ulysses Syndrome" Brussels, Seat of European Parliament. November 5, 2003.

Baistow, K. (2000). The Emotional and Psychological Impact of Community Interpreting. London: Babelea 2000.

Barrick, M. R., \& Mount, M. K. (2005). Yes, personality matters: Moving on to more important matters. Human Performance, 18, 359-372.

Brisau, A., Godijns, R., \& Meulemen, C. (1994). Towards a psycholinguistic profile of the interpreter. Meta, 39(1), 26-48.

Bontempo, K., \& Napier, J. (2011.) Evaluating emotional stability as a predictor of interpreting competence and aptitude for intepreting. Interpreting, 13(1), 85-105.

Bošković, I. (2011). Del estudiante de interpretación al intérprete en los servicios: ¿cómo afecta el estrés al ejecutar el trabajo? (Master's thesis, Master in Intercultural Communication, Public Service Interpreting and Translation). University of Alcalá, Madrid, Spain. To be published in Repositorio E_Buah: http://dspace.uah.es/dspace/handle/10017/17681-

Cole, C. (2010). Performing South Africa's Truth Commission: Stages of Transition. Indiana: Indiana University Press, 121-158.

Cordero Cid, R. (2013). Prevención del síndrome de Burnout en intérpretes en los servicios públicos. (Master's thesis, Master in Intercultural Communication, Public Service Interpreting and Translation). University of Alcalá, Madrid, Spain. 
Retrieved from: http://biblio.uah.es/uhtbin/cgisirsi/?ps=dGqsp4Vl4w/CEXPERIM/285980020/88 . (Accessed October 2015).

Gile, A. (1995). Basic Concepts and Models for Interpreter and Translator Training. Amsterdam: John Benjamins.

Jiang, L. (2007). From 'Community Interpreting' to 'Discourse Interpreting': Establishing some useful parameters. In H. Gerzymisch-Arbogast \& G. Budin (Eds.), Proceedings of the Marie Curie Euroconference: MuTra:LSP Translation Scenarios - Vienna, 30 April-4 May 2007. EU High Level Scientific Conference Series. Retrieved from: http://www.euroconferences.info/proceedings/2007_ Proceedings/2007_Jiang_Lihua.pdf. (Accessed May 2014).

Kurz, I. (2002). Physiological stress responses during media and conference interpreting. In G. Garzone \& M. Viezzi (Eds.), Interpreting in the 21st Century: Challenges and Opportunities. Selected papers from the 1st Forlì Conference on Interpreting Studies, 9-11 November 2000, 195-202. Amsterdam/Philadelphia, John Benjamins.

Kurz, I. (1997). Interpreters: Stress and situation dependent control of anxiety. In K. Klaudy \& J. Kohn (Eds.), Transferre Necesse Est. Proceedings of the 2nd International Conference on Current Trends in Studies of Translation and Interpreting, 201- 206. Budapest: Scholastica.

Loutan, L., Farinelli, T., \& Pampallona, S. (1999) Medical interpreters have feelings too. Sozial-und Praventivmedizin, 44, 280-282.

Magalhães, E. (2012). Afraid? Who is afraid? The ATA Chronicle, 4l(3), 11-13 (Retrieved from: http://ewandromagalhaes.tempsite.ws/ARQUIVOS/PDF/ATA_ CHRONICLE_MAR12.PDF) (Accessed May 2014).

Maslach, C. (1982). Burnout, the Cost of Caring. Englewood Cliffs, N.J.: Prentice Hall.

Márquez Olalla, S. (2013). Impacto psicológico. El estrés, causas, consecuencias y soluciones. Intérprete de conferencias frente a intérprete en los servicios públicos. (Master's thesis. Master in Intercultural Communication, Public Service Interpreting and Translation). University of Alcalá, Madrid, Spain. Retrieved from: http://biblio.uah.es/uhtbin/cgisirsi/?ps=dGqsp4Vl4w/C-EXPERIM/28598 0020/88. (Accessed October 2015).-

Martín, M., \& Phelan, M. (2009). Interpreters and cultural mediators. Different but complementary roles. Translocations: Migration and Social Change, 9(1). Retrieved from: http://www.academia.edu/250428/Interpreters_and_Cultural_ Mediators_-_different_but_complementary_roles.

Maslach, C., \& Leiter, M. P. (1997). The Truth about burnout: How organizations cause personal stress and what to do about it (2nd ed.). San Francisco, CA: Jossey-Bass.

Maslach, C., Jackson, S.E,, \& Leiter, M.P. (1996). MBI: The Maslach burnout inventory: manual. Palo Alto: Consulting Psychologists Press.

Merlini, R., \& Favaron, R. (2003). Community interpreting: Re-conciliation through power management. The Interpreters' Newsletter, 12, 205-229.

Mikkelson, H. (1996). Community interpreting: An emerging profession. Interpreting, l(1), 125-129.

Miller, M. (2005). The Role of interpreters in psychotherapy with refugees. An exploratory study. American Journal of Orthopsychiatry, 75(1), 27-39.

Moser-Mercer, B. (1985). Screening potential interpreters. Meta, 30(1), 97-100.

Moser-Mercer, B., Künzli, A., \& Korac, M. (1998). Prolonged turns in interpreting: Effects on quality, physiological and psychological stress, Interpreting, 3(1), 4764.

Musacchio, M. (2013). El impacto psicológico de los intérpretes en el ámbito de la salud mental: el caso del sindrome de Ulises. (Master's thesis. Master in Intercultural Communication, Public Service Interpreting and Translation). University of Alcalá, Madrid, Spain. Retrieved from: http://biblio.uah.es/uhtbin/cgisirsi/?ps=dGqsp4Vl4w/C-

EXPERIM/285980020/88 . (Accessed October 2015).Navarro Moreno, S. (2012). Interpretación en los servicios públicos. Impacto psicológico y emocional en el intérprete. Análisis de casos y situaciones. (Unpublished Master's thesis, Master in Intercultural Communication, Public Service Interpreting and Translation). University of Alcalá, Madrid, Spain. To be published in Repositorio E_Buah: http://dspace.uah.es/dspace/handle/10017/ 17681. 
O’Brien, A., Terry, D. J. \& Jimmieson, N. L. (2008). Negative affectivity and responses to work stressors: An experimental study. Anxiety, Stress and Coping 21 (1), 5583.

Pérez Rodríguez, B. (2011). Impacto psicológico en TISP. (Unpublished Master's thesis. Master in Intercultural Communication, Public Service Interpreting and Translation). University of Alcalá, Madrid, Spain. To be published in Repositorio E_Buah: http://dspace.uah.es/dspace/handle/10017/17681.

Riccardi, A., Marinuzzi, G., \& Zecchin, S. (2002). Interpretation and stress. In G. Garzone \& M. Viezzi (Eds.), Interpreting in the 21st Century: Challenges and Opportunities. Selected papers from the 1st Forli Conference on Interpreting Studies, 9-11 November 2000, 93 - 105. Amsterdam/ Philadelphia: John Benjamins, .

Røkenes, O. H. (1992). When the therapist needs an interpreter - what does the interpreter need? The role and the reactions of the interpreter in interpreting in psychological treatment. Linjer, 2(2), 3-7.

Svakova, Z. (2011). Impacto psicológico y emocional en los intérpretes y traductores en los servicios públicos. (Unpublished Master's thesis, Master in Intercultural Communication, Public Service Interpreting and Translation). University of Alcalá, Madrid, Spain. To be published in Repositorio E_Buah: http://dspace.uah.es/dspace/handle/10017/17681..

Tribe, R., \& Raval, H. (2003). Working with interpreters in mental health. Hove \& New York: Brunner-Routledge.

Author, C. (2006). Emotional and psychological effects on interpreters in public services. A critical factor to bear in mind. (Retrieved from the web link: http://www.translationdirectory.com/article537.htm. Accessed May 2014).

Wasko, M. (2010). El impacto emocional del trabajo de los intérpretes en los servicios públicos sanitarios: retos y necesidades. (Unpublished Master's thesis, Master in Intercultural Communication, Public Service Interpreting and Translation). University of Alcalá, Madrid, Spain.To be published in Repositorio E_Buah: http://dspace.uah.es/dspace/handle/10017/17681-

Watson, J. (1987). Interpreter burnout. Journal of Interpretation, 4, 79-85.

Watson, D., \& Clark, L. A. (1984). Negative affectivity: The disposition to experience aversive emotional states. Psychological Bulletin, 96(3), 465-490.

Watson, D., Clark, L. A., \& Tellegen, A. (1988). Development and validation of brief measures of positive and negative affect: The PANAS scales. Journal of Personality and Social Psychology, 54(6), 1063-1070.

Westermeyer, J. (1990). Working with an interpreter in psychiatric treatment. Journal of Nervous and Mental Disease, 178, 745-9. 